Педагогика и психология образования. 2020. № 1

DOI: 10.31862/2500-297X-2020-1-173-179

\title{
О.А. Чекун
}

Российский экономический университет имени Г.В. Плеханова, 117997 г. Москва, Российская Федерация

\section{Цифровая образовательная среда в контексте подготовки студентов-лингвистов к межкультурной коммуникации}

Статья посвящена вопросу подготовки студентов-лингвистов к межкультурной коммуникации с использованием цифровой образовательной среды и разнообразных цифровых инструментов, а также влиянию цифровой образовательной среды на мотивацию студентов к изучению проблем межкультурной коммуникации. Рассматриваются педагогические возможности цифровой образовательной среды и цифровых инструментов в образовательном процессе. Автором проведен опрос студентов-лингвистов факультета «Международная школа бизнеса и мировой экономики» Российский экономический университет имени Г.В. Плеханова, изучающих курса «Введение в теорию межкультурной коммуникации» в условиях данной методики. Результаты исследования показали ее эффективность, подтвердили позитивные изменения в мотивации и понимании межкультурных различий у студентов.

Ключевые слова: цифровая образовательная среда, цифровые инструменты, этноцентристская позиция, этнорелятивистская позиция, вербальная коммуникация, невербальная коммуникация

ССЫЛКА НА СТАТЬЮ: Чекун О.А. Цифровая образовательная среда в контексте подготовки студентов-лингвистов к межкультурной коммуникации // Педагогика и психология образования. 2020. № 1. С. 173-179. DOI: 10.31862/2500297X-2020-1-173-179 
DOI: 10.31862/2500-297X-2020-1-173-179

\section{O. Checkun}

Plekhanov Russian University of Economics, Moscow, 117997, Russian Federation

\section{Digital educational environment in the context of preparing students-linguists for intercultural communication}

The article explores the issues of preparing students-linguists for intercultural communication using a digital educational environment and various digital tools and the impact of the digital educational environment on students' motivation. The author considers the pedagogical potential of the digital educational environment and digital tools in preparing students for intercultural communication. The author conducted a survey for students-linguists of "International School of Business and the World Economy" of Plekhanov Russian University of Economics within the course "Introduction to the Theory of Intercultural Communication" in the context of this methodology. The survey results showed positive changes in motivation and understanding of cross-cultural differences.

Key words: digital educational environment, digital tools, ethnocentric stage, ethnorelative stage, verbal communication, non-verbal communication

CITATION: Checkun O.A. Digital educational environment in the context of preparing students-linguists for intercultural communication. Pedagogy and Psychology of Education. 2020. No. 1. Pp. 173-179. (In Russ.) DOI: 10.31862/2500297X-2020-1-173-179

Подготовка студентов-лингвистов к межкультурной коммуникации необходима для успешного профессионального взаимодействия с представителями других культур.

В новом тысячелетии требования к межкультурной подготовке студентов-лингвистов повышаются. В этой связи возникает необходимость совершенствования процесса обучения, применения современных 
подходов, которые бы позволили вывести межкультурную подготовку студентов на качественно новый уровень.

Все это напрямую связано со стремительным развитием инновационных технологий, темп которого настолько высок, что, по словам немецкого экономиста Клауса Шваба, мы живем в эпоху четвертой индустриальной революции, связанной с появлением смарт-технологий, интеллектуальных роботов, искусственного интеллекта, беспилотных автомобилей, био- и генной инженерии и цифровой экономики, для которой нужны компетентные кадры, способные дать объективный ответ на вызовы меняющегося мира [4].

В этой связи одной из наиболее актуальных задач современного высшего образования является создание цифровой образовательной среды. Данная задача реализуется в рамках федерального проекта «Современная цифровая образовательная среда в Российской Федерации» и является стратегической, нацеленный на создание возможностей для получения качественного образования с использования современных информационных технологий (https://akvobr.ru/cifrovaya_ obrazovatelnaya_sreda_ehto.html).

Цифровая образовательная среда (ЦОС) определяется как:

- открытая совокупность информационных систем, предназначенных для обеспечения различных задач образовательного процесса, ее открытый характер позволяет использовать разные информационные системы в составе цифровой образовательной среды (https://akvobr.ru/ cifrovaya_obrazovatelnaya_sreda_ehto.html);

- совокупность ресурсов, обеспечивающих учебный процесс и процесс управления профессиональной образовательной организацией [1];

- обеспечение формирования ценности к саморазвитию и самообразованию у обучающихся образовательных организаций всех видов и уровней, путем обновления информационно-коммуникационной инфраструктуры, подготовки кадров, создания федеральной цифровой платформы (https://edu-frn.spb.ru/files/iiMBxQ4cNH1BCsaWn2Wq DgFinWeU3rVYpmO6sd33.pdf).

Проведенный анализ позволяет заключить, что в контексте межкультурной подготовки студентов-лингвистов цифровая образовательная среда представляет совокупность цифровых ресурсов, создающих информационно-коммуникационную инфраструктуру, которую моделирует преподаватель, чтобы способствовать погружению обучаемых в сферу иноязычной культуры и формированию межкультурной компетенции. Созданная цифровая среда в контексте обучения межкультурной коммуникации способствует: 
- в познавательном плане - овладеть межкультурной информацией;

- в развивающем плане - формировать психологическую готовность к восприятию других норм поведения, перейти от этноцентристских позиций к этнорелятивистским;

- в воспитательном плане развивает личность в homo moralis (человек духовный), для которого культура становится пространством существования;

- в учебном плане - формировать критическое мышление, автономию личности, позволяет построить индивидуальную образовательную траекторию [3].

Созданная цифровая образовательная среда в контексте подготовки студентов к межкультурной коммуникации открывает доступ к самым современным ресурсам, среди которых:

- учебные интерактивные курсы на платформах МOOК (Массовые открытые образовательные курсы), разработанные профессорами ведущих мировых университетов, доступные для широкой аудитории через Интернет, которые являются новейшей технологией, создающей уникальную онлайн языковую образовательную среду для эффективного обучения как общему, так и профессиональному иностранному языку, и сегодня рассматриваются в качестве целостной информационно-образовательной среды, характеризующейся интегративностью, многоаспектностью, обширностью, открытостью, универсальностью; данные учебные онлайн-курсы следуют как общим принципам развивающего и воспитывающего обучения, научности, связи теории с практикой, активности учащихся, доступности, использования индивидуальных и коллективных форм обучения, рефлексии, обратной связи, так и специфическим принципам - междисциплинарности, гипертекстуальности, интерактивности. Наиболее популярные цифровые образовательные платформы для учебных онлайн-курсов: a) FutureLearn - 2012, Открытый университет, Англия; б) Coursera 2012, проект Стэнфордского университета, США; в) EdX (adiks) 2012, академическая платформа, совместный продукт Гарвардского университета, Массачусетского технологического института и Калифорнийского университета в Беркли [2];

- системы управления обучением (LMS), например, Moodle - представляет один из видов LMS в качестве модульной динамической учебной виртуальной образовательной среды, позволяющей создавать и размещать курсы для онлайн-обучения; Canvas LMS (2011) - для организации учебного курса на основе активного обучения, развивающего критическое мышление, умение работать в групповых проектах; 
- разнообразные цифровые инструменты, которые способствуют развитию умений самостоятельной учебной деятельности, рефлексии, самооценки личностных достижений, ответственности за принятие решений, примеры цифровых инструментов для подготовки студентов к межкультурной коммуникации: Padlet - для обучения идиомам, межкультурным особенностям лексики, грамматики, для создания досок, на которую студенты прикрепляют нужную информацию, а также для создания документов, веб-страниц, timeline; Mind map (ментальная карта), для обобщения, систематизации материала, планирования проектов; Socrative представляет из себя инструмент для проведения тестирований на занятиях в учебных заведениях; Edmodo - платформа для общения, сотрудничества и обучения обмена контентом, распределения тестов, заданий и управления общением со студентами; TypeWith.me - инструмент для совместного создания доклада или проекта;

- цифровые инструменты для коммуникации: Facebook, Twitter, VKontakte - социальные сети создают возможности коммуникации со всеми участниками образовательного процесса; WhatsApp или Viber - быстрые мессенджеры, удобные для создания групп, для сообщений, загрузки аудио- и видеоинформации.

Создаваемая цифровая образовательная среда может быть следующих видов:

а) полностью онлайн цифровая образовательная среда, когда все обучение проходит в сети Интернет;

б) цифровая образовательная среда в смешанном обучении, представляющая интегрирование аудиторных занятий и самостоятельных онлайн-занятий в цифровой образовательной среде.

Используемые цифровые инструменты в обучении иностранным языкам в целом, и в подготовке студентов-лингвистов к межкультурной коммуникации в частности, должны соответствовать поставленным целям и этапам урока.

Для студентов-лингвистов факультета «Международная школа бизнеса и мировой экономики» РЭУ им. Г.В. Плеханова, изучающих курс «Введение в теорию межкультурной коммуникации», была разработана цифровая образовательная среда в смешанном обучении. Разработанная ЦОС была направлена на то, чтобы сделать процесс обучения межкультурной коммуникации наиболее рациональным и эффективным. Используемые разнообразные цифровые инструменты (Youtube, Padlet, Mindmap, Kahoot и др.) соответствовали стилю мышления современных студентов, для которых характерно образно-эмоциональное мышление. 
Цифровые инструменты использовались как в цифровой образовательной онлайн-среде для самостоятельной работы, так и на аудиторных занятиях. Опрос, проведенный после окончания курса, показал следующие результаты: 90\% студентам было интересно работать с цифровыми технологиями, проходить тестирование на Kahoot, слушать лекции на TED talks, смотреть видео по изучаемым темам на Youtube, работать над проектами, создавать презентации и т.д.; 70\% студентов понимают, как могут проявляться культурные различия в вербальной и невербальной коммуникации; $60 \%$ студентов отметили переход от этноцентристских позиций на этнорелятивистские.

Таким образом, проведенное исследование подтвердило большие образовательные возможности цифровых технологий и цифровой образовательной среды для подготовки студентов-лингвистов к межкультурной коммуникации и необходимость дальнейшего исследования их образовательного потенциала.

\section{Библиографический список / References}

1. Лапин В.Г. Цифровая образовательная среда как условие обеспечения качества подготовки студентов в среднем профессиональном образовании // Инновационное развитие профессионального образования. 2019. № 1 (21). C. 55-59. [Lapin V.G. Digital educational environment as a condition for ensuring the quality of student training in secondary vocational education. Innovative Development of Vocational Education. 2019. No. 1 (21). Pp. 55-59. (In Russ.)]

2. Чекун О.А. Интеграция массовых открытых онлайн-курсов в обучение иностранному языку студентов неязыковых специальностей МПГУ // Педагогика и психология образования. 2016. № 1. С. 71-74. [Chekun O.A. Integration of mass open online courses into foreign language training of students of non-language specialties of MPGU. Pedagogy and Psychology of Education. 2016. No. 1. Pp. 71-74. (In Russ.)]

3. Чекун О.А. Педагогические условия подготовки студентов к межкультурной коммуникации (на примере неязыковых вузов): Дис. ... канд. пед. наук. М., 2007. [Chekun O.A. Pedagogicheskie usloviya podgotovki studentov k mezhkulturnoy kommunikatsii (na primere neyazykovykh vuzov) [Pedagogical conditions for preparing students for intercultural communication (on the example of non-language universities)]. PhD Diss. Moscow, 2007.]

4. Шваб К. Четвертая промышленная революция. М., 2016. [Schwab K. Chetvertaya promyshlennaya revolyutsiya [Fourth Industrial Revolution]. Moscow, 2016.] 
Сведения об авторе / About the author

Чекун Ольга Алексеевна - кандидат педагогических наук, доцент; доцент кафедры иностранных языков № 2, Российский экономический университет имени Г.В. Плеханова, г. Москва

Olga A. Chekun - PhD in Pedagogy; associate professor at the Departments of Foreign Languages № 2, Plekhanov Russian University of Economics, Moscow

E-mail: checkun@mail.ru 